\title{
Erratum to: Polyphenols and Performance: A Systematic Review and Meta-Analysis
}

\author{
Vaughan Somerville $^{1}$ (D) Cameron Bringans ${ }^{2} \cdot$ Andrea Braakhuis $^{1}$
}

Published online: 22 February 2017

(C) Springer International Publishing Switzerland 2017

\section{Erratum to: Sports Med \\ DOI 10.1007/s40279-017-0675-5}

Page 8, column 1, section 4, paragraph 4, lines 4-8: The following sentence, which previously read:

"The average intake of polyphenols in studies included in the meta-analysis was $688 \mathrm{mg} \cdot \mathrm{day}^{-1}$, which equates to a dietary intake of approximately $200 \mathrm{~g}$ of dark chocolate, $250 \mathrm{ml}$ of green tea and $300 \mathrm{mg}$ of mixed berries (blackcurrant, strawberry and blackberry) [60]."

should read:

"The average intake of polyphenols in studies included in the meta-analysis was $688 \mathrm{mg} \cdot \mathrm{day}^{-1}$, which equates to a dietary intake of approximately $200 \mathrm{~g}$ of dark chocolate, $250 \mathrm{ml}$ of green tea and $300 \mathrm{~g}$ of mixed berries (blackcurrant, strawberry and blackberry) [60]."

The online version of the original article can be found under doi:10.1007/s40279-017-0675-5.

Vaughan Somerville

vsom721@aucklanduni.ac.nz

1 Department of Nutrition and Dietetics, Faculty of Medical and Health Science, The University of Auckland, Auckland, New Zealand

2 Department of Surgery, Faculty of Medical and Health Science, School of Medicine, The University of Auckland, Auckland, New Zealand 